\title{
Modeling the Influence of Weather and Climatic Conditions on the Safety Characteristics of the Construction Process
}

\author{
Vadim Evseev ${ }^{1 *}$, Reza Barkhi $^{2}$, Aleksandr Pleshivtsev ${ }^{3}$ and Anton Scrynnik ${ }^{4}$ \\ ${ }^{1}$ Plekhanov Russian University of Economics, Stremyanny per., 36, Moscow, 117997, Russia \\ ${ }^{2}$ Virginia Polytechnic Institute and State University, Pamplin Hall, Suite 3007,Blacksburg, VA 24061, \\ USA \\ ${ }^{3}$ Moscow State University of Civil Engineering, Yaroslavskoe shosse 26, Moscow, 129337, Russia \\ ${ }^{4}$ V.A. Trapeznikov Instutute of Control Sciences of Russian Academy of Sciences, st.Profsouznaya, 65, \\ Moscow, 117997,Russia
}

\begin{abstract}
This study investigates the influence of climatic conditions on the performance of the construction process and the characteristics of the elements of the construction process: construction machines, workers, the estimated cost of construction, and the reliability of construction deadlines. As an integral indicator of weather and climatic conditions, the indicator of "weather hardness"was chosen. The method of simulation modeling with its ability to generate random numbers with the given parameters is chosen as a mathematical model on a computer. The aim of the study is to identify the regression and correlation relationships between the indicators of weather hardness and the corresponding indicators of the elements of the construction process: the Fund for working time of workers, the coefficient of technical readiness of construction equipment, increasing the estimated cost of construction, increasing labor costs for the re-installation of construction equipment, identification of additional costs by types of work,for all the stated dependencies, regression equations are obtained.The results are presented in graphical form, and the results show that the proposed simulation model of the impact of weather and climatic conditions on the characteristics of the construction process allows to optimize management decisions, and reduce construction risks, reduce the estimated cost of construction.
\end{abstract}

\section{Introduction}

The territory of Russia is divided into seven climatic zones [2] in which economic activity takes place and in which new infrastructure facilities in the industrial and social spheres are being created. Taking into account the peculiarities of climate impact in the construction of infrastructure facilities is implemented in the form of a "Set of rules. Construction climatology (Building climatology)" Updated edition. SNIP (codes and regulations) 23-0199 [3]. The code of rules is made for the purpose of increase of level of safety of people in buildings and constructions and safety of material values according to the Federal law, dated December 30, 2009 N 384-FZ (Federal Law), "Technical regulations on safety of

\footnotetext{
*Corresponding author: manrus@mail.ru,reza@vt.edu
} 
buildings and constructions", increase of level of harmonization of normative requirements with the European and international normative documents, application of uniform methods of determination of operational characteristics and methods of an assessment.

Currently, economic and mathematical methods are widely used to optimize the management, organization, planning and forecasting of construction processes; linear programming models, inventory management models, dynamic programming models, game theory models, graphic models and network models, simulation models, and few others $[4,5,6,7]$. In our work we will investigate the influence of weather and climatic conditions on the characteristics of the construction process using the method of simulation. The choice of the simulation method is largely due not only to the probabilistic characteristics of weather and climatic conditions, but also to a set of probabilistic characteristics of the elements of the construction process. Figure 1 shows the schedule of construction works that are implemented during the year, i.e. in different weather and climatic conditions.

It is also necessary to recall the content of the concepts of reliability and safety in construction:

1) organizational and technological reliability of construction means the ability of technological, organizational, managerial and other decisions to ensure the implementation of the main indicators of construction: the planned time, cost and standard quality of construction of the object under the influence of disturbing factors inherent in the construction as a complex dynamic system. [8-10]

2) the Safety of the construction object is a condition in which there is no unacceptable risk [11-13] associated with causing harm to the life or health of citizens, property of individuals or legal entities, state or municipal property, the environment, life or health of animals and plants due to destruction, damage to the construction object, violation of safety requirements during the construction of such object. [14-16]

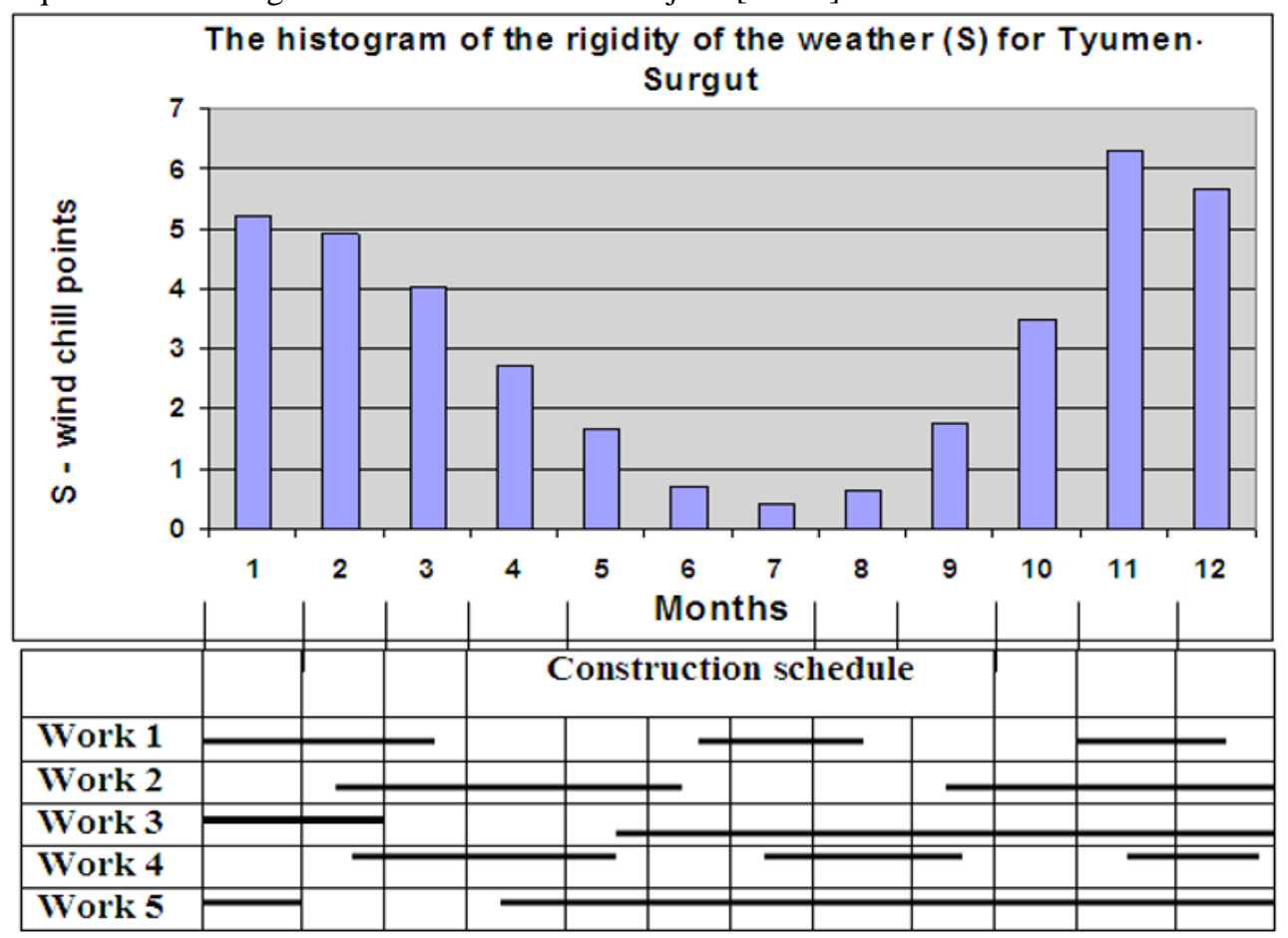

Fig. 1. The histogram of the hardness of the weather and the construction schedule. 


\section{Materials and Methods}

Weather and climatic conditions in our work is considered and calculated as the concept of "weather hardness". Weather hardness is a term that refers to the sensations of a person under the simultaneous influence of frost and wind and is calculated according to the following formula (1) and is applied taking into account its gradation (data are taken from the climate directory):

$$
\mathrm{S}=(1-0.04 \mathrm{~T})(1+0.272 \mathrm{~V})
$$

where: $\mathrm{S}$ - weather hardness (points); T-air temperature (degrees); V-wind speed (m/ sec); Graduation $\mathrm{S}$ : $(\mathrm{S}<1)$ - non - level, soft; $\mathrm{S}=(1-2)$ - little severe, $\mathrm{S}=(2-3)$ - moderately severe; $S=(3-4)$ - severe; $S=(4-5)$ - very severe; $S=(5-6)$ - severely severe; $S=$ (more than 6) - extremely severe.

Since in the climate reference data on temperature and wind speed are given as averages with intervals of deviations, for the implementation of these values in the model uses a random number sensor with a normal distribution law, which has the possible values of temperature and wind during the days of each month. For each month, the weather hardness index is calculated (see Fig.1). Also included in the simulation model are regression relationships between the indicators of weather hardness and the quality of construction machines, indicators of the complexity of repair of construction equipment, increase in the cost of repairs, injuries, accidents.

\section{Results and Discussion}

The interface of the simulation model allows you to immediately obtain the results of the influence of weather and climatic conditions on the indicators of the construction process in the form of graphs and tables.

Let us consider some dependencies of the influence of weather and climatic conditions on the characteristics of workers and the characteristics of the working time Fund. As an example, consider Figure 2, where the number of working days per month of construction is calculated, where workers require special working conditions, i.e. additional 15 and 20 minute breaks for temperature rehabilitation due to the limit values of weather hardness and the creation of appropriate rehabilitation procedure. The model also calculates the probability [17-19] of absenteeism due to diseases associated with severe weather. Figure 3 shows the dependence of the possible values of injuries of construction workers due to the severity of the weather. It should be noted that not taking into account these dependencies as construction risks in the construction schedule can lead to failure of construction terms, as well as to an increase in the cost of construction. These dependencies are securityrelated. 


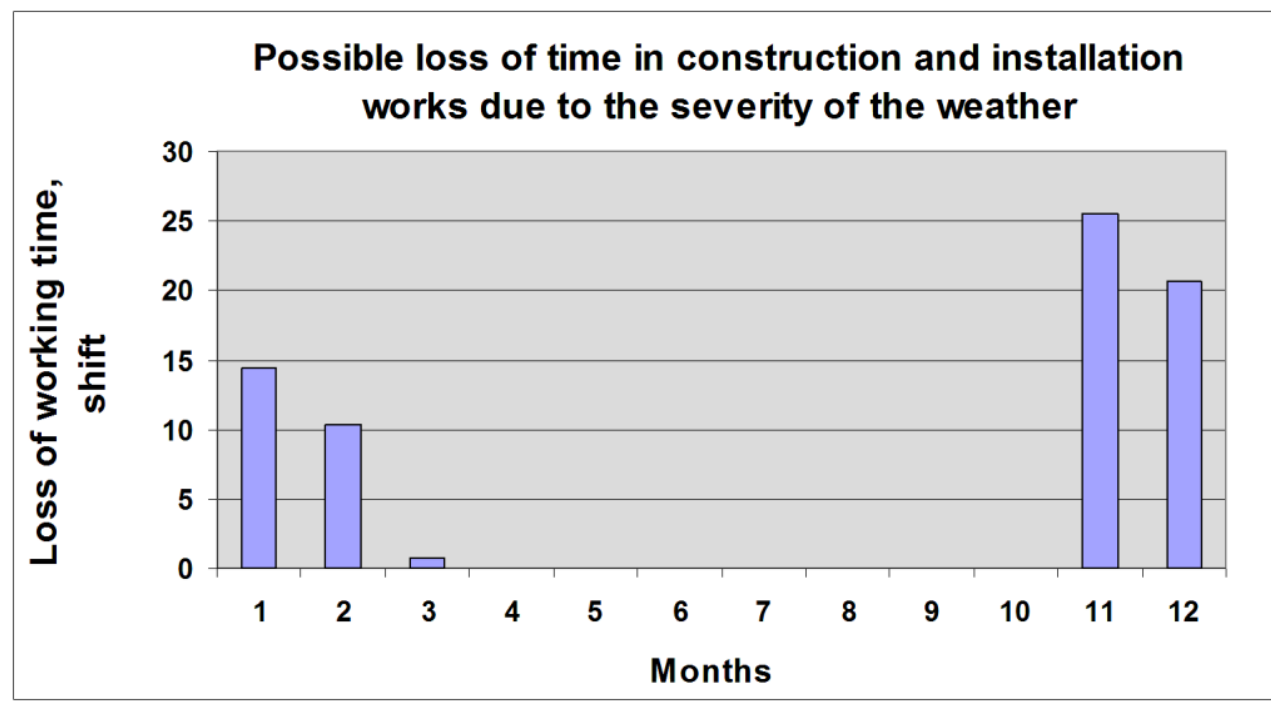

Fig. 2. Number of days where special working conditions are required for the workers due to the extreme stiffness values of the weather.

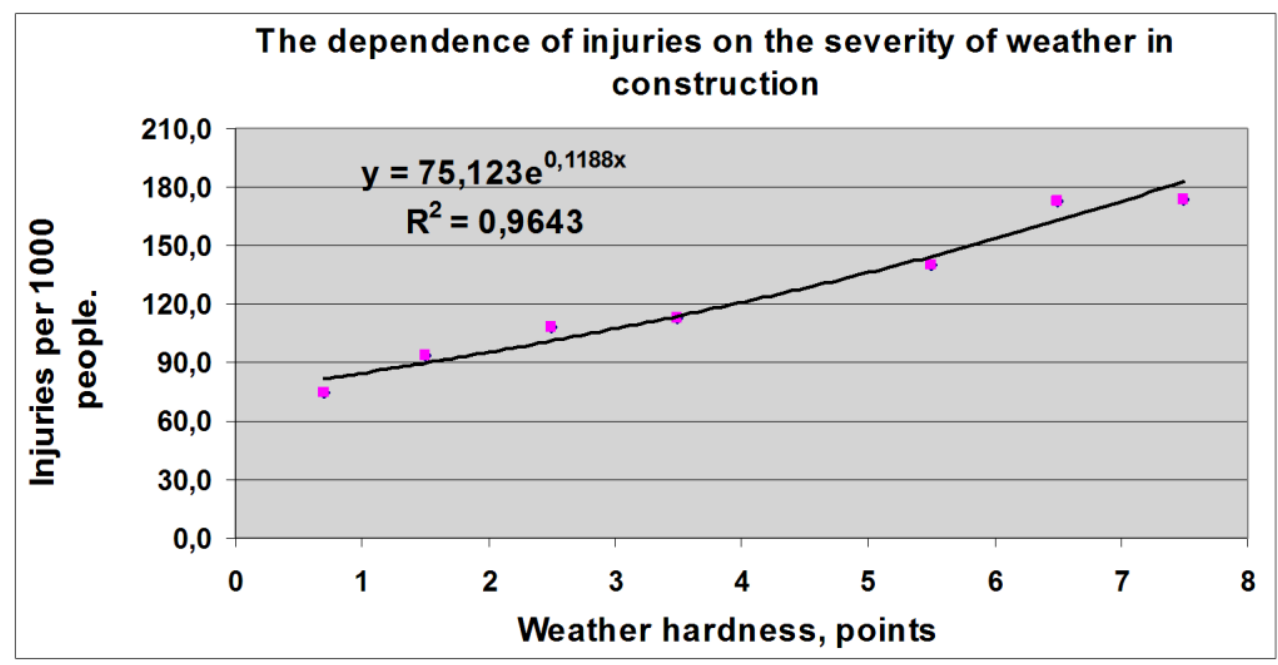

Fig. 3. Injuries to construction workers and severe weather. 


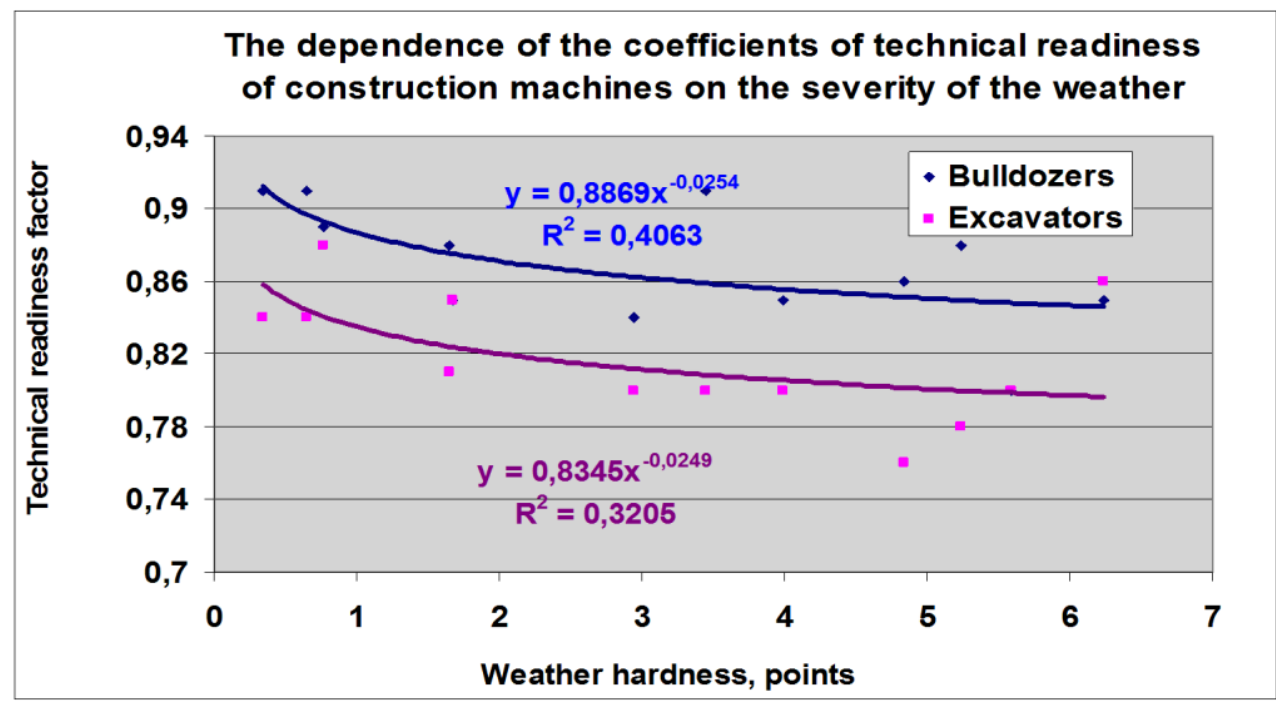

Fig. 4. The influence of the rigidity of the weather on availability of cars.

Consider some of the effects of weather and climatic conditions on the characteristics of construction machines, which relate to reliability. Figure 4 shows an example of the relationship between weather hardness indicators and the coefficient of technical readiness of construction machines, which decreases as the value of the gesture-bone work. This dependency allows you to determine the number of healthy machines that will be in the active state. Figure 5 shows the dependence of increasing the complexity of machine repair as the weather hardness increases.

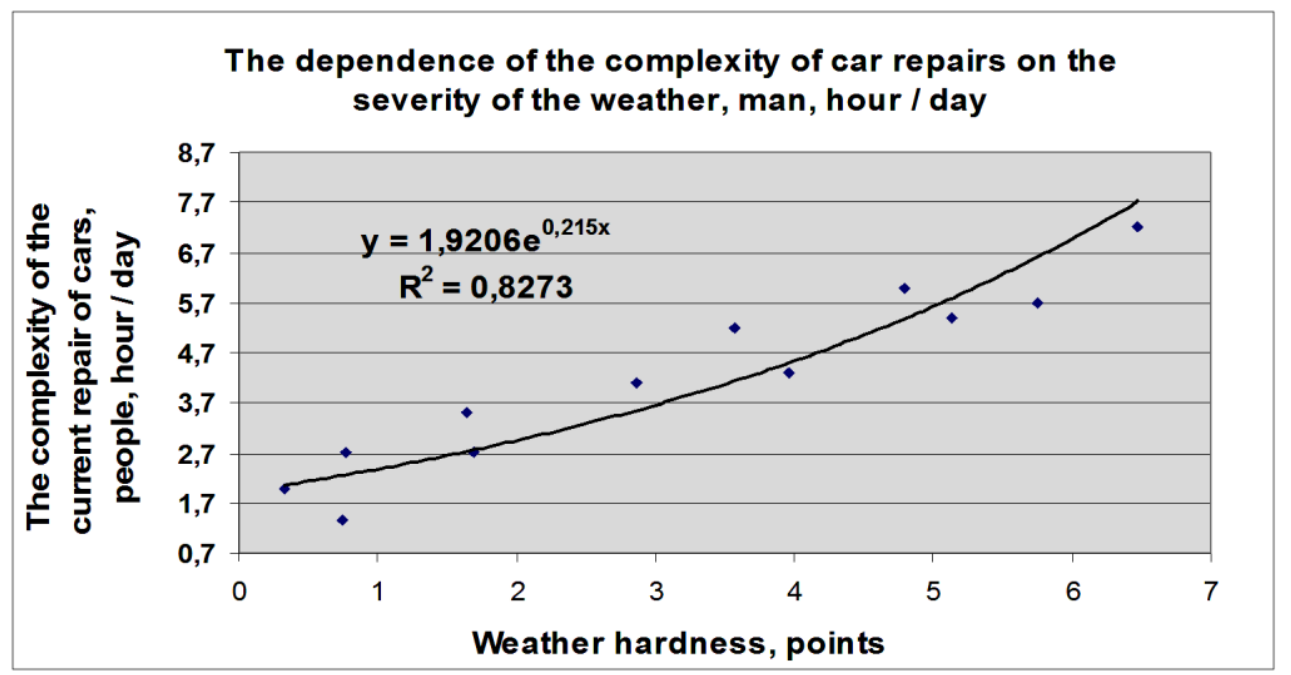

Fig. 5. The influence of the rigidity of the weather on the complexity of the repair machinery. 


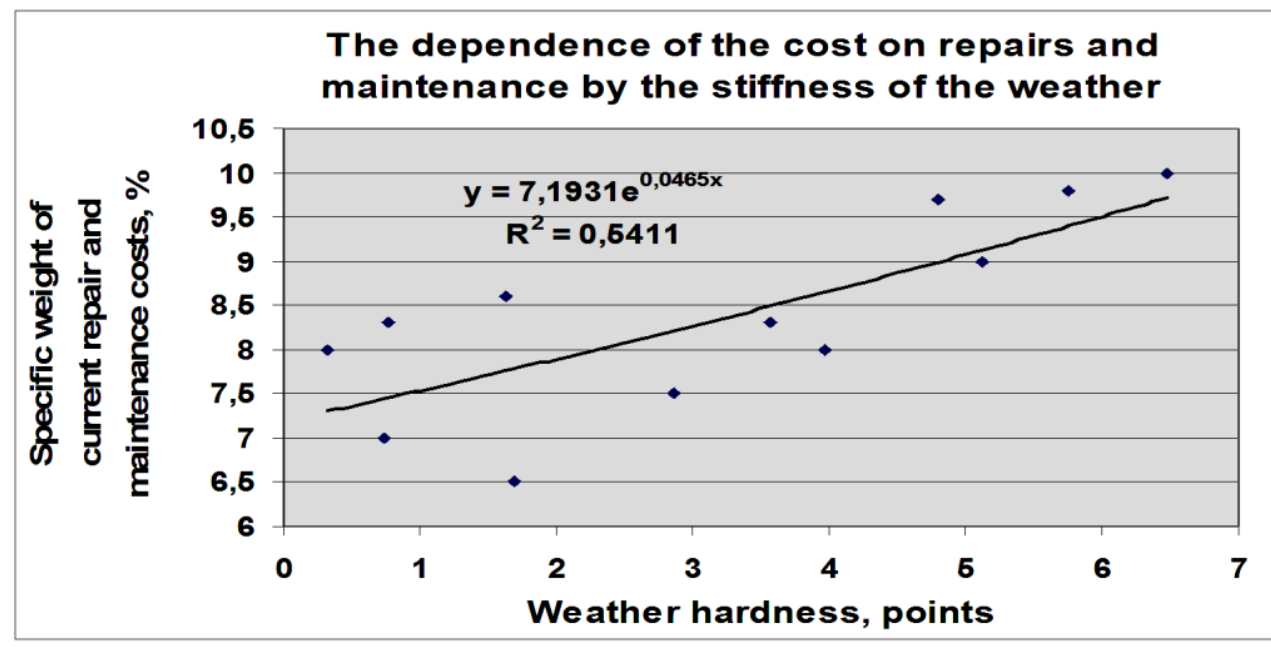

Fig. 6. The influence of the rigidity of the weather on the cost of repairs of machinery.

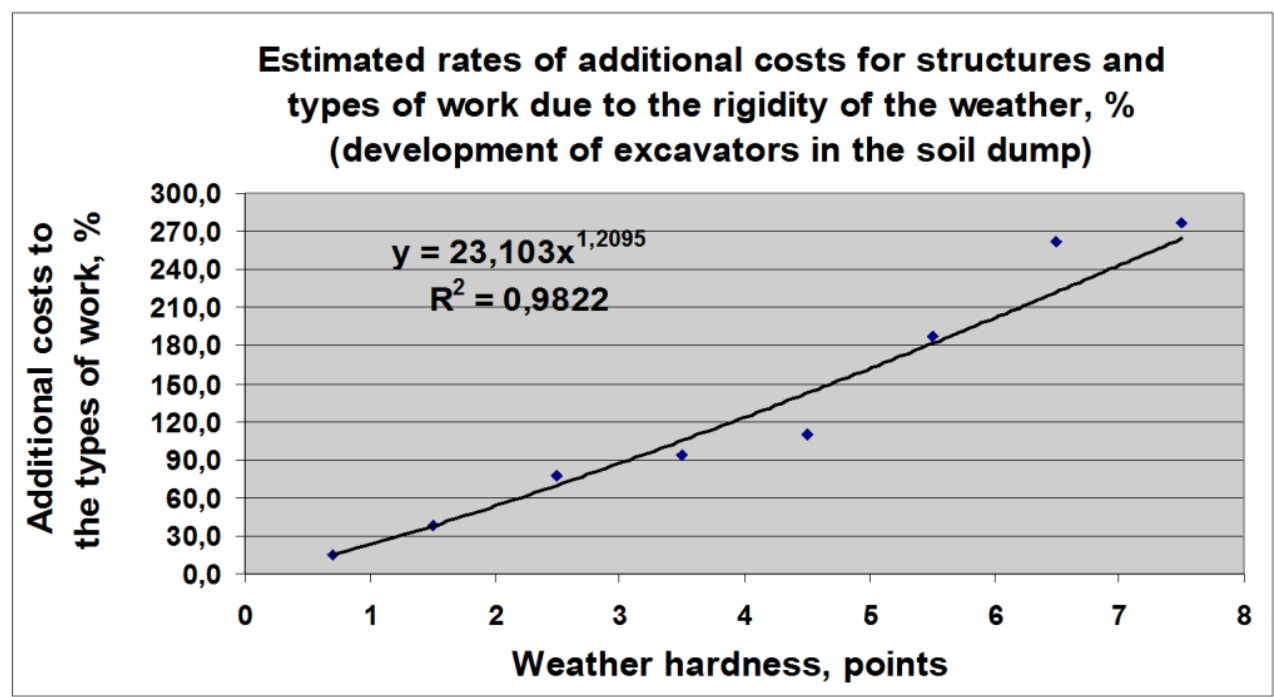

Fig. 7. The influence of the rigidity of the weather additional costs. 


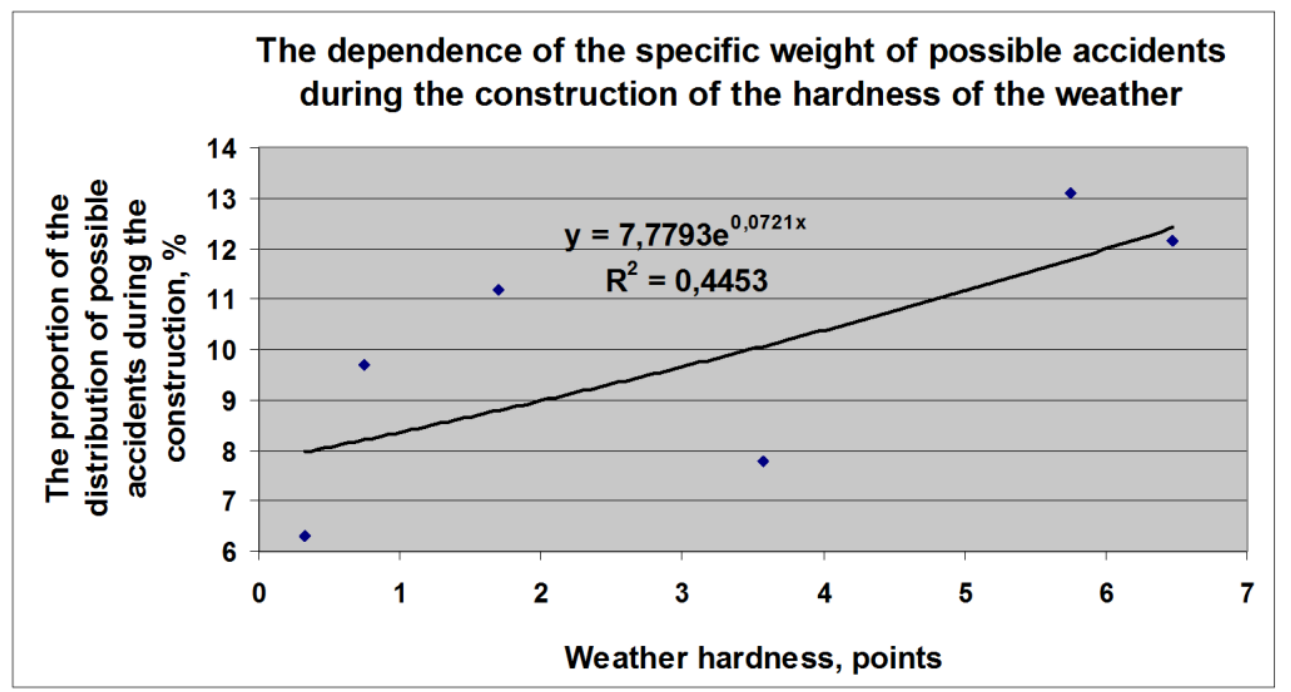

Fig. 8. The influence of the rigidity of the weather for a possible accident.

Weather and climatic conditions affect the economic characteristics [21-24] of the construction. Figure 6 shows the dependence of the increase in the cost of repairs, depending on the indicators of weather hardness, i.e. these dependences lead us to an increase in economic indicators of construction and a possible increase in construction time.

Figure 7 shows the dependence of the influence of weather hardness on the increase in the estimated rates of additional costs by type of work, in our example, the development of excavators in the soil dump.

The apotheosis of the lack of reliability of the construction process are accidents at construction sites and their dependence on the severity of the weather (coef. Corr. $=0.67$ ) (see Fig.8).

The model allows you to change the initial terms of construction stages by type of work in the online mode and immediately receive the interface information we are interested in, in graphical and tabular form.

\section{Conclusions}

Regression dependences (with a high level of correlation coefficient) between the weather hardness and a certain set of characteristics of the elements of the construction process, which must be taken into account when assessing construction risks, are obtained.

As can be seen from the graphs, weather and climatic conditions affect all elements of the construction process: workers, construction machines, technology, logistics, materials used, etc., i.e. affect the safety and reliability of construction.

Weather and climatic conditions increase construction risks, which are taken into account increases the estimated cost of construction, both due to the introduction of additional country reserves, and due to the possible increase in construction time.

The use of simulation models in construction allows the models to develop options for decision - making, allows you to find optimal and rational solutions that contribute to the delivery of construction projects on time, reduces construction risks, and improve the reliability and safety of the construction process. 


\section{References}

1. Order of the Ministry of regional development of the Russian Federation №624 "on approval of the List of types of works on engineering surveys for the preparation of project documents, construction, reconstruction, overhaul of capital construction projects that affect the safety of capital construction projects" dated December 30, 2009.

2. Order of the Ministry of economy of the Russian Federation of 06.05.99 N 240 "about the approval of methodical recommendations about formation of standards of consumption of services of housing and communal services" [Electronic resource ] URL: http://www.zakonprost.ru/content/base/11820/pdf.

3. SP (set of Rules Russian Federation) 131.13330.2012 Construction climatology. The updated edition of SNiP 23-01-99* (with Changes N 1, 2). [Electronic resource ] URL: http://docs.cntd.ru/document/1200095546.

4. Ivanova S. S. Mathematical modeling in construction. Educational and methodical manual. Comp.- Izhevsk: publishing house of ISTU, 2012. - 100 p.

5. Gusakov A. A. and others. Modeling and application of computer technology in the construction industry. M.: Stroizdat, 1979.

6. Kotelnikov, V. V., Chetverikov N. P. Andrievsky R. A., Ananiev A. A. Safety of construction and implementation of the construction control Method. benefit. Moscow: JSC "Scientific and technical center "Industrial safety", 2012; 256 p.

7. Guidelines for the application of the simulation method in the flow construction of the linear part of the main pipelines (P 331-78) .-Moscow: VNIIST,1979. [[Electronic resource ] - URL: http://files.stroyinf.ru / Index2 / 1/4293791/4293791988.htm.

8. Borkovskaya V.G. The concept of innovation for sustainable development in the construction business and education. Applied Mechanics and Materials. (Volumes 475476). Chapter 15: Engineering Management. December 2013. Pages 1703-1706. DOI: 10.4028/www.scientific.net/AMM.475-476.1703.

9. Borkovskaya V.G. Complex models of active control systems at the modern developing enterprises. Advanced Materials Research (Volumes 945-949). Chapter 22: Manufacturing Management and Engineering Management. June 2014. Pages 30123015. DOI: 10.4028/www.scientific.net/AMR.945-949.3012.

10. Borkovskaya V.G. Environmental and economic model life cycle of buildings based on the concept of "Green Building". Applied Mechanics and Materials 467. Materials Science and Mechanical Engineering. Chapter 2: Building Materials and Construction Technologies. Pages 287-290. December 2013. DOI: 10.4028/www.scientific.net/AMM.467.287.

11. BorkovskayaV.G. Bardenwerper W. Roe R. Interactive Teaching of Risk Management in the Russian Construction Industry. IOP Conf. Series: Materials Science and Engineering 365 (2018) 062030 doi:10.1088/1757-899X/365/6/062030.

12. Polyakova V., Degaev E.N., Pierre El Haddad. Reduction of Ecological and Economic Risks in Utilization of Solid Domestic Wastes and Construction Waste. MATEC Web $\begin{array}{llll}\text { of } & \text { 251, } 06017 & \text { (2018). }\end{array}$ https://doi.org/10.1051/matecconf/201825106017.

13. Degaev E.N. New classification of Foaming Agents for Fire Extinguishing. MATEC Web of Conferences. 193, 02032 (2018). DOI: https://doi.org/10.1051/matecconf/201819302032.

14. Degaev E.N., Orlov A, Pierre El Haddad and Pleshivtsev A. Ecological and Economic Risks of Fire Protection of Warehouses and Tank Parks. MATEC Web of Conferences. 251, 06013 (2018).DOI: https://doi.org/10.1051/matecconf/201825106013. 
15. Borkovskaya V.G., Degaev E., Burkova I. Environmental economic model of risk management and costs in the framework of the quality management system // MATEC Web of Conf., 193 (2018) 05027. DOI: https://doi.org/10.1051/matecconf/201819305027.

16. Borkovskaya V.G, Bardenwerper W, Roe R. Sustainability Risk Management: The Case for Using Interactive Methodologies for Teaching, Training and Practice in Environmental Engineering and Other Fields. Book: Smart Technologies and Innovations in Design for Control of Technological Processes and Objects: Economy and Production Chapter No: 25 Chapter. FarEastCon 2018, SIST 138. DOI:10.1007/978-3-030-15577-3_25.

17. Borkovskaya V, Passmore D. Application of Failure Mode and Effects Analysis in Ecology in Russia. MATEC Web of Conf., 193 (2018) 05027. DOI: https://doi.org/10.1051/matecconf/201819305026.

18. Burkov V.N., Burkova I.V., Barkhi R., Berlinov M. Qualitative Risk Assessments in Project Management in Construction Industry. Journal MATEC Web of Conferences, Volume 251, 06027 (2018). DOI: https://doi.org/10.1051/matecconf/201825106027.

19. BorkovskayaV.G, Passmore D. Behavioral engineering model to identify risks of losses in the construction industry. Book: Smart Technologies and Innovations in Design for Control of Technological Processes and Objects: Economy and Production Chapter No: 24 Chapter. FarEastCon 2018, SIST 138. DOI:10.1007/978-3-030-15577-3_24

20. Telichenko V, Rimshin V, Eremeev V, Kurbatov V Mathematical modeling of groundwaters pressure distribution in the underground structures by cylindrical form zone (MATEC Web of Conferences 196,02025, 2018)

21. Varlamov A A, Rimshin V I., Tverskoi S Y The General theory of degradation (IOP Conference Series: Materials Science and Engineering 463(2),022028, 2018).

22. Rimshin V I, Varlamov A A Three-dimensional model of elastic behavior of the composite (Izvestiya Vysshikh Uchebnykh Zavedenii, Seriya Teknologiya Tekstil'noi Promyshlennosti. (3), 2018).

23. Evseev V.O Osipov V.S., Skryl T.V An analysis of economic issues of territories of priority Development.Research Journal of Applied Sciences. 2016. T. 11. № 9. C. 833842.

24. Evseev V. O. Human resources in the system of socio-economic equations: studies. Benefit 2nd ed.].:- M.: high school textbook, INFRA-M, 2017. - 379 p. 